\title{
ÁREA DE CONCENTRAÇÃO EM DIREITOS HUMANOS DA USP: INCLUSÃO E INOVAÇÃO
}

\author{
Fábio Konder Comparato ${ }^{1}$ \\ Celso Lafer ${ }^{2}$ \\ Enrique Ricardo Lewandowski ${ }^{3}$ \\ Calixto Salomão Filho ${ }^{4}$ \\ Alberto do Amaral Jr. ${ }^{5}$ \\ Carlos Portugal Gouvêa ${ }^{6}$
}

\section{Introdução}

Este artigo pretende registrar a história e ressaltar o impacto da fundação da área de concentração em Direitos Humanos da Faculdade de Direito do Largo de São Francisco (FDUSP). Para tanto, os autores analisaram a bibliografia já existente sobre o tema e levaram em conta também a própria experiência como coordenadores e professores, além de terem buscado documentos cedidos pela Fundação Carlos Chagas, empenhando-se na realização de entrevistas com personalidades que tiveram papel de destaque nesse processo. ${ }^{7}$ Este texto tem o valor de registro histórico e aponta as contribuições da área de concentração para a ciência jurídica contemporânea, além de

1 Professor emérito da Faculdade de Direito da Universidade de São Paulo (FDUSP). Doutor honoris causa da Universidade de Coimbra, ex-presidente da Comissão de Justiça e Paz, fundador da Escola de Governo de São Paulo, doutor em Direito pela Université Paris 1 (Panthéon-Sorbonne) e ex-coordenador do conselho da área de Direitos Humanos.

2 Professor emérito da Universidade de São Paulo, da Faculdade de Direito e do Instituto de Relações Internacionais da USP. Recebeu o título de doutor honoris causa de várias universidades estrangeiras. Membro da Academia Brasileira de Ciências e da Academia Brasileira de Letras, ex-ministro das Relações Exteriores e ex-coordenador do conselho da área de Direitos Humanos.

3 Professor titular da Faculdade de Direito da Universidade de São Paulo, ministro do Supremo Tribunal Federal e ex-coordenador do conselho da área de Direitos Humanos.

4 Professor titular da Universidade de São Paulo, professor do Institut de Sciences Politiques, em Paris, e ex-coordenador do conselho da área de Direitos Humanos.

5 Professor associado da Faculdade de Direito da Universidade de São Paulo, foi visiting scholar da Yale Law School, é atual diretor da Sociedade Latino-Americana de Direito Internacional e coordenador do conselho da área de Direitos Humanos.

6 Doutor em Direito pela Universidade de Harvard (S.J.D.) e bacharel em Direito pela Universidade de São Paulo. Atualmente, é professor doutor da Faculdade de Direito da Universidade de São Paulo, ligado ao Departamento de Direito Comercial e à área de concentração de Direitos Humanos.

7 Os autores agradecem as contribuições de Allyne Andrade e Silva, Denise Dora, Joana Zylbersztajn e Sandra Unbehaum. Também estendem seus agradecimentos à Fundação Carlos Chagas e a Joana Zylbersztajn, por tornarem disponível documentos importantes sobre os anos iniciais do programa, assim como pelo apoio de Gustavo Manicardi Schneider e Cynthia Maria Santos Bezerra nas atividades de pesquisa. 
discutir o papel que desempenhou como primeiro programa da Universidade de São Paulo a adotar ações afirmativas.

Este texto é composto de quatro partes. A primeira descreve o processo que criou a área de concentração. A segunda analisa a adoção de políticas afirmativas pelo programa e a importância histórica dessa decisão. A terceira apresenta os principais aspectos que fazem a área de concentração situar-se, hoje, na vanguarda do pensamento jurídico no Brasil, com um currículo abrangente e rigoroso às temáticas inovadoras das teses defendidas por alunos que se tornaram mestres e doutores. A quarta e derradeira parte conclui ao demonstrar o êxito indiscutível alcançado pela iniciativa.

\section{Origem do curso e história precedente}

A criação da área de concentração em Direitos Humanos foi aprovada pelo Conselho de Pós-graduação da Universidade de São Paulo (USP) no dia 2 de junho de 2005.

A criação da área de concentração em Direitos Humanos decorreu do resultado de décadas de acúmulo de produção acadêmica e de atividade didática, devido à atuação histórica dos professores Dalmo Dallari, ${ }^{8}$ Fábio Konder Comparato, ${ }^{9}$ Celso Lafer ${ }^{10}$ e Enrique Ricardo Lewandowski. ${ }^{11}$ Tais professores publicaram as obras fundacionais que deram início à reflexão intelectual sobre os Direitos Humanos no Brasil e criaram, também, os primeiros cursos sobre a matéria em nível de pós-graduação, os quais permitiram formar uma nova geração de professores, a fim de propagar a pesquisa e a reflexão sobre Direitos Humanos em nosso país. A criação da área de Direitos Humanos, do ponto de vista geral, teve uma forte motivação axiológica: a da relevância

8 O professor Dalmo Dallari é autor de Direitos Humanos e cidadania, um dos principais livros que propagou o estudo do tema no Brasil. Ver DALLARI, Dalmo de Abreu. Direitos Humanos e cidadania. São Paulo: Moderna, 1998.

9 O professor Fábio Konder Comparato é também autor de A afirmação histórica dos Direitos Humanos, obra pioneira sobre o tema e até hoje um dos livros mais vendidos em Direitos Humanos no Brasil. Ver COMPARATO, Fábio Konder. A afirmação histórica dos direitos humanos. São Paulo: Saraiva, 1999.

$10 \mathrm{O}$ professor Celso Lafer é também autor de obras seminais para o debate brasileiro, como A reconstrução dos direitos humanos e A internacionalização dos direitos humanos. Ver LAFER, Celso. A reconstrução dos direitos humanos: um diálogo com o pensamento de Hannah Arendt. São Paulo: Companhia das Letras, 1988; e LAFER, Celso. A internacionalização dos direitos humanos: constituição, racismo e relações internacionais. Barueri-SP: Manole, 2005.

11 O professor Lewandowski foi um dos pioneiros na produção acadêmica sobre o tema, tendo refletido sobre os Direitos Humanos em sua tese de doutorado, intitulada Origem, estrutura e eficácia das normas de proteção dos direitos humanos na ordem interna e na ordem internacional, publicada em 1982. Nesse trabalho, foi orientado pelo professor Dalmo Dallari, também pioneiro no tema. Ver LEWANDOWSKI, Enrique Ricardo. Proteção dos direitos humanos na ordem interna e internacional. Rio de Janeiro: Forense, 1984. 
da afirmação dos Direitos Humanos como caminho para o indispensável aprimoramento da convivência coletiva.

No segundo semestre de 1974, o professor Vicente Marotta Rangel, com a assistência do professor Celso Lafer, ministrou um curso de pós-graduação na FDUSP, no âmbito do Departamento de Direito Internacional (DIN 731), intitulado "Direito Internacional da pessoa humana". À época, tratou-se de grande ousadia, pois o curso ocorreu no auge da Ditadura Militar. O professor Celso Lafer regeu o curso nas ausências e impedimentos do professor Marotta Rangel. Esse foi o ponto de partida do professor Celso Lafer na jornada de dedicação aos Direitos Humanos. O fato está registrado na conferência que ministrou no $26^{\circ}$ Congresso Mundial do IVR, realizado em Belo Horizonte em 2013 e subsequentemente publicado no número 146 da Archiv für Rechts- und Sozialphilosophie: "Human Rights Challenges in the Contemporary World: Reflections on a Personal Journey of Thought and Action", de 2015.

O professor Dalmo Dallari credenciou em 4 de junho de 1984 os cursos "Direitos Humanos fundamentais" e "Proteção dos Direitos Humanos". Criou também, em 12 de agosto de 1991, o curso "A proteção dos Direitos Humanos no plano interno dos Estados e no plano internacional". Os dois primeiros cursos foram posteriormente assumidos pelos professores Enrique Ricardo Lewandowski e Celso Lafer. Além destes, o curso "Teoria fundamental dos Direitos Humanos" começou a ser ministrado em 1994 pelo professor Fábio Konder Comparato.

Alguns anos antes da criação da área de concentração em Direitos Humanos, em 2001, a Fundação Ford solicitou a elaboração de um relatório sobre o estado da arte do ensino de Direitos Humanos nas universidades brasileiras. O relatório indicou que havia naquele momento quatro modelos de ensino de Direitos Humanos no país, mediante a introdução na grade de cursos de graduação e pós-graduação de: (i) disciplinas específicas de Direitos Humanos; (ii) disciplinas afeitas à área de Direitos Humanos; (iii) temáticas e abordagens relacionadas a Direitos Humanos em disciplinas tradicionais; e, também, por intermédio de (iv) cursos de extensão e especialização em Direitos Humanos. Entre as propostas do relatório, estava a criação de um curso de mestrado em Direitos Humanos (UNBEHAUM; LEÃO; FEITOSA, 2012).

Os dados do relatório chamaram a atenção da então program officer da Fundação Ford no Brasil, Denise Dora. Sua percepção era a de que, embora já houvesse ativismo em prol de Direitos Humanos em organizações do terceiro setor e partidos políticos, ainda faltava um programa acadêmico que tratasse em profundidade do tema no Brasil.

A partir das conclusões obtidas, criou-se o programa "Desenvolvendo a infraestrutura de Direitos Humanos no Brasil", que tinha três objetivos: consolidar cinco ou seis organizações de Direitos Humanos no país, com capacidade para redigir 
relatórios, registrar violações de direitos e formalizar denúncias; estruturar um campo acadêmico e de pesquisa em Direitos Humanos; e instituir um fundo que apoiasse essas organizações. O programa que deu origem à área de concentração em Direitos Humanos da Faculdade de Direito da USP visava ao segundo desses objetivos.

O modelo do programa adotado pela Fundação Ford não era novo. Ela já havia concedido financiamento a outros projetos no Brasil. Trata-se de um modelo de dotações (grants) via edital elaborado em parceria com uma entidade brasileira. A opção, à época, privilegiou a parceria com a Fundação Carlos Chagas, que já tinha coordenado o "Programa de dotações para pesquisa sobre mulheres" entre os anos de 1978 e 1998. A partir do trabalho conjunto dessas duas entidades, lançou-se, então, o edital do "I Programa de dotações para mestrado em Direitos Humanos no Brasil”, que contemplaria até três universidades com doações de 270 mil reais.

Entre os requisitos do edital, três deles merecem realce: a obrigação de multidisciplinaridade dos cursos oferecidos, de maneira que abordassem também perspectivas de gênero, raça/etnia e exclusão social; a necessidade de aliar a teoria à prática em Direitos Humanos, por meio de convênios com outras universidades para intercâmbio de docentes e discentes, além de estágio em instituições governamentais e não governamentais; e o requisito de criação de políticas afirmativas para o processo de seleção do programa (FUNDAÇÃO CARLOS CHAGAS, 2003).

A mesma perspectiva de inclusão que orientava o requisito de políticas afirmativas guiava também o processo de seleção das universidades que seriam contempladas pelo programa de dotações. Denise Dora, em entrevista concedida aos autores, explica a importância do critério regional:

O critério regional era muito importante. Não queria que fossem escolhidas apenas faculdades do Rio de Janeiro e de São Paulo. Recebemos uma proposta muito boa da Federal do Pará e outra proposta muito boa da Federal da Paraíba. [...] Para mim, também era importante que fossem incluídas as universidades do Norte, onde estudariam pessoas indígenas, ou pessoas que vêm de comunidades quilombolas. Nem a Universidade Federal do Pará, nem a da Paraíba são universidades de elite do país. [...]. A Universidade Federal da Paraíba [era uma] universidade pequena, com poucos recursos, mas que já tinha um núcleo de Direitos Humanos importante, organizado por Luciano Maia, que contava com participantes das faculdades de Filosofia e de Economia. Tratava-se de um projeto diferente dos que tínhamos até aquele momento e integrado com o ativismo regional. Já a USP era exatamente o oposto. A importância da escolha está exatamente em sua condição de universidade de elite. A USP e a Faculdade de Direito da USP. [A FDUSP] É a faculdade que mais 
formou ministros da suprema corte. Se quiséssemos que a gramática de Direitos Humanos influenciasse o debate jurídico e chegasse aos tribunais superiores, precisávamos ter em mente uma universidade de elite.

Por atender aos requisitos do edital e aos critérios regionais, foram escolhidas a Universidade Federal do Pará, a Universidade Federal da Paraíba e a Universidade de São Paulo para atribuição da dotação prevista no edital. Além de se comprometerem com o atendimento dos requisitos solicitados no edital, as universidades, ao receberem as dotações, também se comprometeram com o acompanhamento do programa nos três anos seguintes pela Fundação Carlos Chagas e pela Fundação Ford.

Na USP, o professor Fábio Konder Comparato foi escolhido para coordenar o programa, que viria a ser um dos três primeiros mestrados em Direitos Humanos do Brasil. Ademais, ainda que não sem dificuldades, seria também o primeiro programa da Universidade de São Paulo com reserva de vagas.

O programa foi oficialmente aprovado pela USP no dia 2 de junho de 2005, em despacho publicado no Diário Oficial do Estado de São Paulo. Dias depois, em 10 de junho, publicou-se o primeiro edital para seleção de pós-graduandos com a possibilidade de ingresso na área de concentração em Direitos Humanos. Foram 177 inscritos, número que representava $11 \%$ dos candidatos para o processo seletivo de pósgraduação da Faculdade de Direito da Universidade de São Paulo, que abarcava também todos os outros departamentos e diferentes programas oferecidos (SANTOS, 2010).

Desde o projeto inicial, buscava-se a abordagem interdisciplinar para superar a dominante análise formalista do Direito. O programa contava com a colaboração de professores de diferentes departamentos da Faculdade de Direito e com professores de outras unidades da Universidade de São Paulo.

Vale mencionar que a Faculdade de Direito da USP, quando aprovada no edital da Fundação Ford, já havia criado um curso de especialização em Direitos Humanos. O referido curso surgiu da parceria com o Centro de Direitos Humanos (CDH), uma associação civil que nasceu a partir do projeto de extensão do centro acadêmico XI de Agosto, então coordenado pelos professores Fábio Konder Comparato, Dalmo de Abreu Dallari e Maria Victória Benevides, esta da Faculdade de Educação.

O curso de especialização já tinha sido ministrado duas vezes, uma delas em parceria com a Escola Superior do Ministério Público da União, e, naquele momento, tinha grade interdisciplinar, contando com a participação de professoras da Faculdade de Educação.

A parceria com o Centro de Direitos Humanos abriu caminho para viabilizar a área de concentração em Direitos Humanos, além de ter contribuído diretamente na elaboração do projeto enviado à Fundação Carlos Chagas. 
Além disso, a experiência prévia com os cursos de especialização já demonstrara a existência de demanda pelo estudo de Direitos Humanos em nível de pósgraduação na USP. A propósito, o segundo ano de existência do programa contou com quase 50 alunos. $^{12}$

\section{Políticas afirmativas: inclusão e Direitos Humanos}

Conforme mencionado, a realização de processos seletivos com políticas afirmativas era requisito expresso do edital. O motivo dessa decisão pela Fundação Ford e pela Fundação Carlos Chagas foi explicado por Denise Dora em entrevista:

Estávamos introduzindo o debate de Direitos Humanos. Não existia nenhuma possibilidade de fazermos isso só com a classe média alta branca do país, porque Direitos Humanos exigem uma alavancagem. Exigem, de um lado, que as pessoas que sofrem as violações de Direitos Humanos se posicionem e enfrentem as desigualdades. E exigem, do outro lado, que as pessoas mais abastadas no país estejam dispostas a abrir mão de privilégios, com o fim de alcançar uma sociedade justa e equilibrada. A despeito de o programa privilegiar escolas de elite, como eram certas universidades naquela época, era importante ampliar o diálogo de modo a integrar novos participantes.

Este pensamento - que, em 2003, representava a vanguarda dos Direitos Humanos - não foi, entretanto, de fácil execução. A área de concentração em Direitos Humanos da pós-graduação da FDUSP foi o primeiro programa da Universidade de São Paulo a incluir em todos os níveis políticas afirmativas no processo seletivo, fato essencial para a mobilização do corpo docente por políticas de inclusão que se consolidaram nos anos seguintes.

Os questionamentos formais feitos às políticas afirmativas acabaram dificultando a implantação de um programa fortemente inclusivo em um primeiro momento. Mantiveram-se as provas de inglês e de conhecimentos jurídicos, de caráter eliminatório. Como consequência, no primeiro processo seletivo, dos 61 inscritos, apenas cinco estudantes que faziam jus às políticas afirmativas foram aprovados. A proporção do número de candidatos para cada aprovado foi ainda $30 \%$ menor entre os alunos não beneficiados pela política afirmativa.

Desse modo, a manutenção das provas de caráter eliminatório foi vista como uma forma de restringir o acesso da população ao programa, já que parte relevante

12 Os dados do curso de especialização e do CDH constam em relatório fornecido por Joana Zylbersztajn. 
dos candidatos não dominava o idioma inglês. Havia, assim, prejuízo para a efetividade das ações afirmativas, ainda que existisse, após as provas, a reserva de um terço das vagas para candidatos negros, pardos, com deficiência física grave ou em condição de vulnerabilidade social.

No relatório final da Fundação Carlos Chagas, o então presidente do conselho da área de concentração, o professor titular Calixto Salomão Filho, reconheceu que havia a necessidade de se pensar em modelos mais eficazes de inclusão.

Não obstante as dificuldades inerentes para pôr em prática políticas públicas ambiciosas, a implantação da reserva de vagas em nível de pós-graduação na Faculdade de Direito foi precursora dos movimentos de inclusão que se seguiram. A própria FDUSP só aprovou cotas raciais para ingresso na graduação em 2017, e o curso de mestrado em Direitos Humanos continua a ser o único curso de pós-graduação com reserva de vagas na faculdade.

Além disso, para apoiar os alunos em situação de hipossuficiência econômica, foram oferecidas bolsas nos primeiros anos do programa, bolsas essas criadas a partir dos recursos das dotações recebidas. Foram três bolsas no primeiro ano do programa e cinco no segundo.

Vale notar que dois dos professores que participaram intensamente do debate sobre as políticas afirmativas no âmbito da área de concentração de Direitos Humanos da FDUSP vieram, mais tarde, a discutir a mesma pauta no Supremo Tribunal Federal, quando do julgamento da "Arguição de Descumprimento de Preceito Fundamental 186", que versava sobre a constitucionalidade das cotas raciais. São eles: o professor Fábio Konder Comparato e o ministro Enrique Ricardo Lewandowski. O primeiro participou de audiência pública em nome da organização Educafro, em defesa das cotas raciais. O segundo, por sua vez, relator da ADPF, proferiu o voto condutor pela improcedência da ação, de tal sorte a permitir a adoção de políticas afirmativas sobre cotas raciais.

De modo semelhante, o professor Celso Lafer elaborou parecer no caso Ellwanger, que versou a publicação e veiculação de obra de caráter racista. O parecer em causa influenciou diretamente o julgamento do Supremo Tribunal Federal a respeito.

\section{Desenvolvimento e contribuições para a ciência jurídica brasileira}

Como já mencionamos, a interdisciplinaridade fazia parte do próprio projeto da Universidade de São Paulo para o edital do programa de dotações, tendo sido um elemento central do currículo desde o princípio do funcionamento da área. Unbehaum, Leão e Carvalho (2014) identificaram que a área de Direitos Humanos da USP era a mais interdisciplinar entre as três beneficiadas pelo programa de dotações, contando com onze docentes de outras unidades da universidade. Importa salientar que 
alguns deles colaboraram desde o início da área, inclusive com a formação no âmbito das atividades de extensão universitária do $\mathrm{CDH}$.

A área de Direitos Humanos, por ser inerentemente interdisciplinar, deu margem a cursos com caráter experimental e de vanguarda na pesquisa em ciências jurídicas e sociais. Cumpriu, assim, o objetivo expresso no edital do programa de dotações: o de superar as abordagens tradicionais formalistas e contribuir para o avanço do estudo do Direito no Brasil.

No início das atividades da área, esse compromisso com a interdisciplinaridade era, também, requisito da grade curricular. Além de cumprir quatro disciplinas obrigatórias, o aluno deveria cursar ao menos uma matéria da temática de Direitos Humanos em outra unidade da USP. As quatro disciplinas obrigatórias compunham um núcleo técnico e histórico dos Direitos Humanos, que seria então complementado com as demais matérias opcionais.

Eram oferecidas duas disciplinas obrigatórias a cada semestre. No primeiro semestre de 2006, foram oferecidas "Teoria fundamental dos Direitos Humanos", ${ }^{13}$ ministrada pelo professor titular Fábio Konder Comparato, e "Direitos Humanos fundamentais", ministrada pelo professor titular Enrique Ricardo Lewandowski. Já no segundo semestre, foram oferecidas "Proteção internacional dos Direitos Humanos", ministrada pelo professor titular Celso Lafer, e "Exclusão Social e políticas de inclusão social", ministrada pela professora titular Walkure Lopes Ribeiro da Silva, pela professora dra. Eunice Aparecida Prudente e pelo professor associado Marcus Orione.

Até o momento, foram criadas na área de concentração de Direitos Humanos 23 disciplinas, segundo informação da base de dados da FDUSP. ${ }^{14}$ Entre elas, há clara prevalência de abordagens que tentam complementar o estudo da normatividade estatal com elementos empíricos. Além disso, uma parcela relevante das disciplinas concentra-se em problemas concretos de grupos específicos (LEÃO; CARVALHO, 2014).

Ainda no corpo docente, havia em 2018 trinta orientadores credenciados, sendo sete de outras unidades (Escola de Artes, Ciências e Humanidades; Faculdade de Educação; Faculdade de Medicina; Faculdade de Filosofia Letras e Ciências Humanas; e Faculdade de Saúde Pública).

Como exemplo do cenário descrito, citamos as disciplinas: "Direitos e diversidades: o tema da luta por reconhecimento e do multiculturalismo no âmbito das teorias da justiça", "Direitos e diversidades: o tema da luta por reconhecimento de direitos

13 Esta disciplina, como mencionado, já era ministrada pelo professor Fábio Konder Comparato antes da existência da área, na pós-graduação, pelo Departamento de Filosofia e Teoria Geral do Direito.

14 O sistema Janus foi consultado em $1^{\circ}$ de fevereiro de 2021, e indicou 41 cadastros de disciplinas com a sigla DHU, sendo que esses cadastros correspondiam a 23 matérias diferentes ao todo, já contando com as duas disciplinas inicialmente obrigatórias. 
para grupos sociais vulneráveis no âmbito das teorias da justiça" e "Epistemologia e ética em pesquisas sobre/com grupos socialmente vulneráveis, periferias e minorias visíveis", oferecidas pela professora dra. Gislene Aparecida dos Santos, vinculada ao curso de Gestão de Políticas Públicas; "Temas fundamentais de Direito à educação"; ministrada pela professora Nina Stocco Ranieri, da FDUSP; "História dos Direitos Humanos e o processo de especificação do sujeito de Direito", ministrada pelos professores dr. Guilherme Assis de Almeida e dra. Bibiana Graeff, ele da FDUSP e ela professora do curso de Gerontologia; "Gênero e etnia: intercessões necessárias aos Direitos Humanos fundamentais para a interlocução sobre as funções do Estado" e "Estudos sobre a violência I - raízes e manifestações", ministradas pela professora dra. Eunice Prudente, da FDUSP; "Direitos Humanos e desenvolvimento econômico e social", ministrada pelo professor titular Calixto Salomão Filho e pelo professor dr. Carlos Portugal Gouvêa; entre outras.

Além de compartilharem o traço comum de abordar o Direito conforme perspectivas inovadoras, as disciplinas também utilizam metodologias ativas de ensino, como aprendizado baseado em problemas e método socrático.

Vale ressaltar também que a disciplina pioneira "Mediação em conflitos de justiça, cultura da paz e promoção dos Direitos Humanos I", ministrada pelo professor dr. Antônio Rodrigues de Freitas Júnior desde 2009, foi laureada pelo Conselho Nacional de Justiça em 2017 com o prêmio "Conciliar é legal”. As teses desenvolvidas no âmbito do programa refletem, ademais, a experiência multidisciplinar dos pós-graduandos. Até 2018, a área de concentração havia formado 44 doutores e 107 mestres, além de contar com 30 mestrandos e 25 doutorandos. Tais números expressivos revelam que o programa atingiu seus objetivos ao formar quadros habilitados a darem aulas e realizarem pesquisa em nível superior em todo o Brasil.

Não é por acaso que temas recentemente abordados no âmbito da pósgraduação em Direitos Humanos envolvem alguns dos assuntos mais pungentes na sociedade em geral e na teoria jurídica contemporânea. Entre esses temas, figuram o Direito à inclusão da pessoa com deficiência, ${ }^{15}$ a reforma do judiciário em virtude da nova dinâmica de ações coletivas ${ }^{16}$ e teorias críticas raciais aplicadas ao Direito brasileiro. ${ }^{17}$ Devemos realçar, ainda, os mecanismos de repressão ao trabalho escravo na atualidade,

15 Dr. Fernando Gaburri estudou o tema na tese Inclusão e igualdade: a reserva de vagas para ingresso das pessoas com deficiência no serviço público.

16 Dra. Helena Refosco analisou o tema na tese Ação coletiva e acesso à justiça: uma análise da reforma do judiciário à luz de estudos de caso.

17 Dra. Allyne Andrade e Silva abordou o tema na tese Uma teoria crítica racial do Direito Brasileiro: aportes teóricos e metodológicos. O dr. Osmar Teixeira Gaspar, orientado pelo professor Kabengele Munanga, estudou em tese de doutorado o tema Direitos políticos e representatividade da população negra na Assembleia Legislativa do Estado de São Paulo e Câmara Municipal de São Paulo. 
as regras jurídicas sobre movimentos migratórios complexos, ${ }^{18} \mathrm{o}$ impacto do judiciário no regime de proteção de terras indígenas, ${ }^{19}$ a função social da propriedade intelectual, ${ }^{20}$ o direito à saúde ${ }^{21} \mathrm{e}$ a ascensão política feminina. ${ }^{22}$

Os docentes da área de concentração em Direitos Humanos participaram de iniciativas de extensão da FDUSP, o que concretiza os elementos centrais dos pilares que compõem a proposta acadêmica da Universidade de São Paulo: ensino, pesquisa e extensão. Vale ressaltar, nesse campo, a iniciativa da Clínica de Direitos Humanos Luiz Gama, agraciada em 2015 por ocasião do $21^{\circ}$ Prêmio Nacional em Direitos Humanos da Secretaria Nacional de Direitos Humanos (SDH), na categoria População em Situação de Rua. A clínica conduz seu projeto principal sob a orientação do professor titular Calixto Salomão Filho, ex-coordenador do programa. O projeto é voltado ao atendimento da população em situação de rua e busca promover mudanças estruturais na academia jurídica a partir das extensões universitárias.

Da mesma forma, vale destacar a Cátedra OEA, grupo orientado pelo professor dr. Alberto do Amaral Jr., atual coordenador da área de concentração, que se dividiu em quatro frentes de trabalho para a discussão e a pesquisa de temas relacionados aos Direitos Humanos na América Latina durante o ano de 2019. O trabalho do grupo foi posteriormente publicado em uma obra comemorativa dos 50 anos da Convenção Americana de Direitos Humanos.

A diversidade de temas engloba também grande pluralidade de metodologias de pesquisa empregadas nas teses aqui mencionadas. A área de Direitos Humanos tem realizado conferências, cursos e seminários com a participação de professores estrangeiros, personalidades da sociedade civil, membros de movimentos sociais e ONGs, com a finalidade de discutir as conexões em nível local, regional e global no plano dos Direitos Humanos. Temas como a democracia e o desenvolvimento sustentável receberam especial atenção. Atua igualmente para promover, por intermédio de "clínicas" e "oficinas", o conhecimento acerca das atividades desenvolvidas pela Comissão e pela Corte Interamericana de Direitos Humanos. A área busca manter um

18 Dra. Camila Sombra Muiños de Andrade discutiu o tema na tese Movimentos migratórios mistos e a condição jurídica de refugiado: uma relação tensional.

19 Dr. Leandro Ferreira Bernardo discorreu sobre o tema na tese Demarcação de terras indigenas e poder judiciário: uma análise crítica do impacto da atuação judicial na garantia das políticas públicas estatais voltadas ao acesso às terras para as populações indígenas na região platina brasileira.

20 Dr. Eduardo Altomare Ariente refletiu sobre o tema na tese A função social da propriedade intelectual.

21 A dra. Daniela Batalha Trettel estudou o tema na dissertação Planos de saúde na justiça: o direito à saúde está sendo efetivado? Estudo do posicionamento dos Tribunais Superiores na análise dos conflitos entre usuários e operadoras de planos de saúde.

22 O tema foi estudado pela hoje doutoranda Marta Barbosa da Costa Nunes na dissertação de mestrado Ascensão política das mulheres: São Tomé e Príncipe-Brasil. 
contato estreito com programas similares existentes no exterior, com o propósito de estimular o intercâmbio de experiências mutuamente vantajosas.

\section{Conclusão}

O presente artigo teve por objetivo registrar a história e destacar o impacto da fundação da área de concentração em Direitos Humanos da Faculdade de Direito do Largo de São Francisco. Dessa forma, reconstruímos os principais fatos que antecederam a criação da área e abordamos dois aspectos principais do programa: a inclusão por meio de políticas afirmativas e a posição de vanguarda no pensamento jurídico brasileiro contemporâneo. Esses dois aspectos se entrelaçam para compor a essência da área, que teve e tem como objetivo o uso do método interdisciplinar para superar o formalismo jurídico. A própria história do curso e as políticas afirmativas no processo seletivo reproduzem os objetivos perseguidos. A inclusão social via políticas afirmativas é, assim, ao mesmo tempo, decisiva ao cumprir a função da universidade pública de trabalhar em prol da população e essencial para que a área continue a ser um polo pioneiro na pesquisa jurídica no Brasil.

\section{Referências}

FUNDAÇÃO CARLOS CHAGAS. I Programa de Dotações para implementação de mestrado em direitos humanos no Brasil. Edital, 2003 (impresso).

LEÃO, Ingrid Viana; CARVALHO, Camila Magalhães. Análise do Currículo da área de concentração em direitos humanos: tensões e desafios da pós-graduação em Direito na USP, UFPA e UFPB. Conselho Nacional de Pesquisa e Pós-graduação em Direito (Conpedi), 2014.

SANTOS, Jocélio Teles dos. Pós-graduação em Direito e as ações afirmativas no Brasil: uma experiência induzida. Revista Pós Ciências Sociais, São Luís, v. 7, n. 14, jul./dez. 2010.

UNBEHAUM, Sandra; LEÃO, Ingrid Viana; CARVALHO, Camila Magalhães. Programas e áreas de concentração em direitos humanos no Brasil: o desenho de uma possível interdisciplinaridade. Revista Interdisciplinar de Direitos Humanos, Bauru, v. 2, n. 3, p. 35-53, jul./dez. 2014.

UNBEHAUM, Sandra; LEÃO, Ingrid Viana; FEITOSA, Victor. A pesquisa em Direitos Humanos: análise preliminar sobre temas de mestrado na UFPA, UFPB e USP. $7^{\circ}$ Encontro Anual da ANDHEP: Direitos Humanos, Democracia e Diversidade, Curitiba, de 23 a 26 de maio de 2012.

VELASCO, Ignacio Maria Poveda. Mestrado em direitos humanos na USP: uma experiência pioneira. In: MARCÍliO, Maria Luiza. (org.). Dez anos da Comissão de Direitos Humanos Universidade de São Paulo. São Paulo: Universidade de São Paulo, 2007, v. 1, p. 171-175. 